\title{
Nonlocal boundary value problems
}

\author{
Daniel Franco', Gennaro Infante $2^{2^{*}}$ and Feliz Manuel Minhós ${ }^{3}$
}

* Correspondence: $g$.

infante@unical.it

${ }^{2}$ Dipartimento di Matematica,

Università della Calabria, 87036 Arcavacata di Rende, Cosenza, Italy

Full list of author information is available at the end of the article
In the last decades, nonlocal boundary value problems have become a rapidly growing area of research. The study of this type of problems is driven not only by a theoretical interest, but also by the fact that several phenomena in engineering, physics and life sciences can be modelled in this way. For example, problems with feedback controls such as the steady-states of a thermostat, where a controller at one of its ends adds or removes heat, depending upon the temperature registered in another point, can be interpreted with a second-order ordinary differential equation subject to a three-point boundary condition.

This volume contains a variety of contributions within this area of research. The first article, by Alberto Cabada, is an invited review on the applications of the method of upper and lower solutions to boundary value problems with nonlinear boundary data. The following articles deal with boundary value problems with nonlocal conditions for ordinary, discrete, impulsive, neutral, parabolic, fractional and time scales equations. The last two papers deal with problems where the nonlocality occurs in the equation, rather than in the boundary conditions.

In the contributions, existence, nonexistence, multiplicity, asymptotic behavior, and approx-imation of solutions are considered by using several methods as fixed point theorems, fixed point index, variational methods, iterative techniques, bifurcation theory, and lower and upper solutions.

We would like to thank the authors for their contributions and the anonymous referees for their professional support.

We wish to thank the staff of the Editorial Office of Boundary Value Problems, for their help throughout the realization of this volume.

It is our great pleasure to thank Professor Ravi P. Agarwal, Editor-in-Chief of Boundary Value Problems, for giving us the opportunity to prepare this volume.

\footnotetext{
Author details

'Departamento de Matemática Aplicada, Universidad Nacional de Educación a Distancia, (UNED), c/ Juan del Rosal 12, Madrid 28040, Spain 2Dipartimento di Matematica, Università della Calabria, 87036 Arcavacata di Rende, Cosenza, Italy ${ }^{3}$ Department of Mathematics, University of Évora, Rua Romão Ramalho, 59, 7000-671, Évora, Portugal
}

Received: 13 April 2011 Accepted: 24 February 2012 Published: 24 February 2012

doi:10.1186/1687-2770-2012-23

Cite this article as: Franco et al:: Nonlocal boundary value problems. Boundary Value Problems 2012 2012:23.

\section{包 Springer}

(c) 2012 Franco et al; licensee Springer. This is an Open Access article distributed under the terms of the Creative Commons Attribution License (http://creativecommons.org/licenses/by/2.0), which permits unrestricted use, distribution, and reproduction in any medium, provided the original work is properly cited. 